\title{
Exotic plant species are locally adapted but not to high ultraviolet-B radiation: a reciprocal multispecies experiment
}

\author{
Maria Hock (DD $1,2,6$ Rainer W. Hofmann, ${ }^{3}$ Caroline Müller,${ }^{4}$ and Alexandra Erfmeier ${ }^{1,5}$ \\ ${ }^{1}$ Institute for Ecosystem Research/Geobotany, Kiel University, Olshausenstrasse 75, Kiel 24118 Germany \\ ${ }^{2}$ Institute of Biology/Geobotany and Botanical Garden, Martin Luther University Halle-Wittenberg, Am Kirchtor 1, Halle 06108 \\ Germany \\ ${ }^{3}$ Faculty of Agriculture and Life Sciences, Lincoln University, Ellesmere Junction RoadlSprings Road, Lincoln 7647 New Zealand \\ ${ }^{4}$ Faculty of Biology/Chemical Ecology, Bielefeld University, Universitätsstraße 25, Bielefeld 33615 Germany \\ ${ }^{5}$ German Centre for Integrative Biodiversity Research (iDiv) Halle-Jena-Leipzig, Deutscher Platz 5E, Leipzig 04103 Germany
}

Citation: Hock, M., R. W. Hofmann, C. Müller, and A. Erfmeier. 2019. Exotic plant species are locally adapted but not to high ultraviolet-B radiation: a reciprocal multispecies experiment. Ecology 100(5):e02665. 10.1002/ecy.2665

\begin{abstract}
Ultraviolet (UV) radiation intensities differ among global regions, with significantly higher levels in the southern hemisphere. UV-B may act as an environmental filter during plant invasions, which might particularly apply to plant species from Europe introduced to New Zealand. Just like for any other abiotic or biotic filter, successful invaders can cope with novel environmental conditions via plastic responses and/or through rapid adaptation by natural selection in the exotic range. We conducted a multispecies experiment with herbaceous plants in two common gardens located in the species' native and exotic ranges, in Germany and New Zealand, respectively. We used plants of German and New Zealand origin of eight species to test for adaptation to higher UV-B radiation in their new range. In each common garden, all plants were exposed to three radiation treatments: (1) ambient sunlight, (2) exclusion of UV-B while transmitting ambient UV-A, and (3) combined exclusion of UV-B and UVA. Linear mixed-effect models revealed significant effects of UV-B on growth and leaf traits and an indication for UV-B-induced biomass reduction in both common gardens pointing to an impact of natural, ambient UV radiation intensities experienced by plants in the northern and in the southern hemisphere. In both common gardens, the respective local plants (i.e., German origins in Germany, New Zealand origins in New Zealand) displayed enhanced productivity and aboveground biomass allocation, thus providing evidence for recent evolutionary processes in the exotic range. Genetic differentiation between different origins in consequence of divergent local selection pressures was found for specific leaf area. This differentiation particularly hints at different selective forces in both ranges while only little evidence was found for an immediate selective effect of high UV-B intensities in the exotic range. However, reaction norm slopes across ranges revealed higher plasticity of exotic individuals in functional leaf traits that might allow for a more sensitive regulation of photoprotection measures in response to UV-B. During the colonization, New Zealand populations might have been selected for the observed higher phenotypic plasticity and a consequently increased ability to successfully spread in the exotic range.
\end{abstract}

Key words: environmental filter; multispecies experiment; native and exotic populations; phenotypic plasticity; plant invasions; recent evolutionary changes; reciprocal common garden; $U V-A$ and $U V-B$ exclosure.

\section{INTRODUCTION}

Plant invasions are globally an increasingly striking and frequent phenomenon mainly fostered by extensive human activity and enhanced economic development (Lodge et al. 2006, Hulme 2009). Most notably, they occur in previously isolated systems, such as islands, with serious consequences for native biodiversity and

Manuscript received 27 February 2018; revised 21 December 2018; accepted 16 January 2019. Corresponding Editor: Samantha K. Chapman.

${ }^{6}$ E-mail: mhock@ecology.uni-kiel.de ecosystem functioning (Kueffer et al. 2010). In consequence, aiming at a better understanding of underlying mechanisms controlling the success or failure of invasions and thereby the identification of plant species and traits that have the potential to respond successfully to novel environmental conditions in new habitats are central research goals in invasion ecology.

The ability of exotic species to cope with novel abiotic and biotic factors is crucial and can be explained by several mechanisms. Release from native biotic and abiotic stressors (Blossey and Nötzold 1995, Lin et al. 2015), pre-adaptation that might match conditions in the new 
range (Schlaepfer et al. 2010, Elst et al. 2016), high phenotypic plasticity in response to a broad environmental range (Ruprecht et al. 2014, Oplaat and Verhoeven 2015), or occupation of a vacant ecological niche (Dlugosch et al. 2015) can be considered classical ecological mechanisms enhancing invasion success. Furthermore, approaches based on the comparison of native and exotic genotypes point to the importance of rapid adaptive evolution for the successful colonization of the exotic range (Ziska et al. 2015). While for some plant invasions it is possible to specifically test and identify single mechanisms as predominant keys, most of the mechanisms are not necessarily mutually exclusive but may act subsequently or even simultaneously in different stages of invasions (Dietz and Edwards 2006, Si et al. 2014, Zenni et al. 2014, Lamarque et al. 2015).

Rapid adaptive evolution in the exotic range has mostly been tested by reciprocal transplant or common garden experiments, since comparing native and exotic populations in (multiple) common environments allows to uncover genetic differentiation of origins in measurable phenotypic traits (Maron et al. 2004, Flory et al. 2011, Müller 2018). According to Kawecki and Ebert (2004), local adaptation can ideally be assessed by testing the "local vs. foreign" criterion among different environments, which hypothesizes a better performance of the local population compared to a foreign population within a particular environment.

Local adaptation was found to occur in invasive species as frequently and as strongly as in native plant species as depicted in a recent meta-analysis on 130 studies (Oduor et al. 2016). Thus, adaptive evolution in consequence of natural selection in the exotic range may apply to many plant species world-wide. Thereby, local adaptation in the novel habitat can be driven by either an environmental constraint or a release: Whereas conditions of constraints mostly lead to specialization by classical natural selection, evolutionary responses to release from stresses might be more often accompanied by phenotypic plasticity (Erfmeier 2013). Nevertheless, there is evidence for phenotypic plasticity to facilitate local adaptation during plant invasions or even be adaptive itself (Nicotra et al. 2010). Especially plant populations with a wide geographic distribution range may display local adaptation to climatic factors correlated with latitude (Felker-Quinn et al. 2013), and there is a high number of such examples for several variables, e.g., day length (Vandepitte et al. 2014), length of growing season (Colautti and Barrett 2013) and temperature (MolinaMontenegro et al. 2013).

Beyond those, also ultraviolet (UV) radiation is a climatic factor that significantly differs in intensity at a global scale and that is largely subjected to effects of global change (Watanabe et al. 2012). Nonetheless, UV radiation has been widely ignored to date as potentially selective environmental filter during plant invasions (but see Beckmann et al. 2012, Hock et al. 2015, Wang et al. 2015). Due to the lower earth-to-sun distance and the higher solar altitude during the southern hemisphere summer, fundamental overall differences in annual and maximum intensities of UV-A (spectral range: 315$380 \mathrm{~nm}$ ) and UV-B radiation (spectral range: 280$315 \mathrm{~nm}$ ) occur between hemispheres. Up to twofold higher UV intensities are observed in the southern hemisphere, in particular, when regions at similar latitude are compared, e.g., temperate Central Europe with temperate New Zealand (Seckmeyer and McKenzie 1992, Godar 2007, McKenzie et al. 2007, 2011). Plants can respond to elevated UV-B radiation with changes in phenology (e.g., a delayed reproductive timing), decreased productivity, a more compact plant architecture and changes in leaf morphology, i.e., reduced stem length, increased branching, thicker leaves with modified leaf shape and altered root: shoot ratios in various directions (Kataria et al. 2014, Llorens et al. 2015, Robson et al. 2015, Suchar and Robberecht 2016). At the cellular level, the main targets of high-energy UV-B radiation are nucleic acids, Calvin cycle enzymes and photosystem II proteins with a significant potential for photosynthesis apparatus damage (Kataria et al. 2014). Thus, UV-B also triggers biosynthesis of sunscreen metabolites, such as phenolics, antioxidants, and DNA repair enzymes (Ulm and Jenkins 2015, Barnes et al. 2016). Due to potential costs involved in these responses, increased UV-B radiation may consequently result in decreased competitive ability and reduced fitness of individuals with potentially negative implications for establishment and colonization in novel environments. UV-A radiation is highly related to UV-B and known for its mitigating effect, as it induces protection measures of the photosynthetic apparatus under abiotic stress conditions (e.g., high UV-B, drought) and therefore increases physiological resilience (Štroch et al. 2015, Escobar-Bravo et al. 2017, Verdaguer et al. 2017). Thus, investigation of UV$B$ radiation effects on individual plants performance and population fitness should be conducted under natural radiation conditions to ensure ecologically relevant UV environments characterized by a particular relation of UV-A, UV-B, and photosynthetically active radiation (PAR: 380-700 nm; Kuhlmann and Müller 2011).

Here, we studied variation in growth traits of individuals from German and New Zealand origins of eight herbaceous plant species exotic in New Zealand in response to UV radiation. We compared performance under each of three UV treatments additionally implemented in two common gardens reciprocally established in the species' "native" (Germany) and exotic range (New Zealand, Fig. 1). Based on the known detrimental effects of UV-B radiation on plants, we tested for evidence of UV-B as a driver of recent adaptive evolution during plant invasions in high-UV-B environments. We, specifically, hypothesized that (1) natural UV-B radiation generally constrains plant performance with stronger growth-limiting effects in the exotic range New Zealand, (2) divergent natural selection has already resulted in differentiation between plant individuals of 


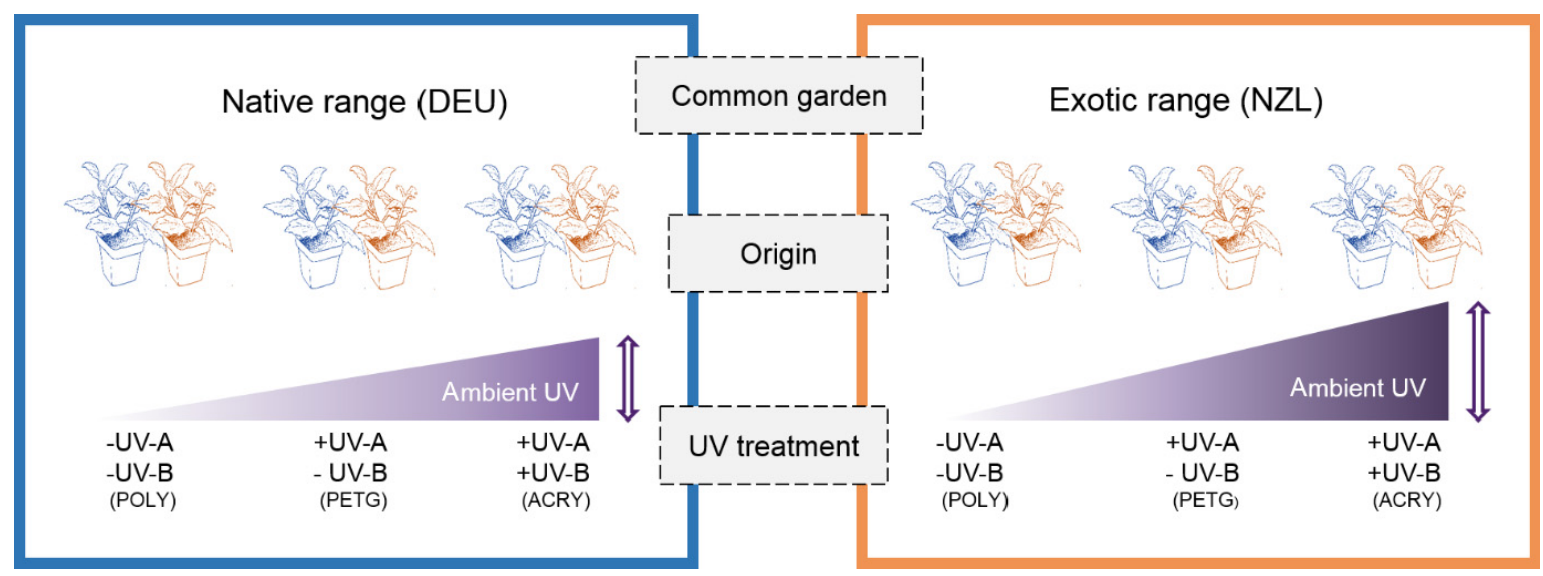

FIG. 1. Experimental design of common garden experiments indicating the factors of common garden, i.e., experimental setting in the two ranges, origin, i.e., population origin of either German or New Zealand provenance, and levels of experimental ultraviolet (UV) treatments. This setting was conducted for each of the eight study species (Appendix S1) in a common design. DEU, Germany; NZL, New Zealand; POLY, polycarbonate (-UV-A|-UV-B); PETG, polyethylene terephthalate glycol (+UV-A|-UV-B); ACRY, acrylic (+UV-A|+UV-B).

German and New Zealand origins due to different local selection pressures, and (3) local populations in the exotic range New Zealand have specifically adapted to elevated UV-B and therefore show higher UV-B tolerance. Alternatively, higher UV-B tolerance may be a result of selection for high phenotypic plasticity during colonization. To our knowledge, this is the first study addressing local adaptation of exotic species to elevated UV-B intensities in the exotic range via a multispecies reciprocal common garden approach.

\section{Methods \\ Experimental design}

We conducted a common garden experiment including individuals of eight herbaceous species (Table 1) in, both, the native range (Germany) and the exotic range (New Zealand). In Germany, the experiment was performed in the Botanical Garden of Kiel University $\left(54.34583^{\circ} \mathrm{N}, 10.11632^{\circ} \mathrm{E}\right)$ during the northern hemisphere summer season 2015 (July-October), whereas the New Zealand common garden was established at Lincoln University $\left(43.64506^{\circ} \mathrm{S}, 172.4620^{\circ} \mathrm{E}\right)$ during the southern hemisphere summer season 2014-2015 (December-March).

In both common gardens, German and New Zealand individuals of all study species were grown. The investigated species represent a subset of a larger species pool included in another experimental approach within the described setting (M. Hock et al., unpublished data) and were selected based on seed availability for both ranges. All eight species prefer open, unshaded habitats, are fully naturalized in New Zealand (Allan Herbarium 2000, Howell and Sawyer 2006) and, hereafter, considered to be native to Europe although they comprise different
TABlE 1. Study species, the year of recorded naturalization in New Zealand (according to the New Zealand Plant Conservation Network database), and their experimental duration in days in both common garden experiments in New Zealand (NZ) and Germany (DE).

\begin{tabular}{|c|c|c|c|c|}
\hline \multirow[b]{2}{*}{ Species } & \multirow[b]{2}{*}{ Family } & \multirow{2}{*}{$\begin{array}{c}\text { Year } \\
\text { naturalized }\end{array}$} & \multicolumn{2}{|c|}{$\begin{array}{r}\text { Experimenta } \\
\text { duration }(\mathrm{d})\end{array}$} \\
\hline & & & NZ & $\mathrm{DE}$ \\
\hline $\begin{array}{l}\text { Artemisia } \\
\text { absinthium L. }\end{array}$ & Asteraceae & 1872 & $102 \dagger$ & $75 \dagger$ \\
\hline $\begin{array}{l}\text { Erysimum } \\
\text { cheiri }(\mathrm{L} .) \\
\text { Crantz }\end{array}$ & Brassicaceae & 1875 & 107 & 75 \\
\hline $\begin{array}{l}\text { Linaria } \\
\text { purpurea } \\
\text { (L.) Mill }\end{array}$ & Scrophulariaceae & 1875 & $77 \dagger$ & $76 \dagger$ \\
\hline $\begin{array}{l}\text { Lobularia } \\
\text { maritima } \\
\text { (L.) Desv. }\end{array}$ & Brassicaceae & 1840 & $73 \dagger$ & $77 \dagger$ \\
\hline $\begin{array}{c}\text { Origanum } \\
\text { vulgare } \mathrm{L} .\end{array}$ & Lamiaceae & 1944 & $78 \dagger$ & $77 \dagger$ \\
\hline $\begin{array}{l}\text { Tragopogon } \\
\text { porrifolius } \mathrm{L} .\end{array}$ & Asteraceae & 1870 & 104 & 74 \\
\hline $\begin{array}{l}\text { Trifolium } \\
\text { pratense } \mathrm{L} .\end{array}$ & Fabaceae & 1867 & $78 \dagger$ & $73 \dagger$ \\
\hline $\begin{array}{l}\text { Trifolium } \\
\text { repens } \mathrm{L} .\end{array}$ & Fabaceae & 1864 & $79 \dagger$ & $74 \dagger$ \\
\hline
\end{tabular}

$\dagger$ Species that reached the reproductive stage during the experiments.

degrees of nativeness (Germplasm Resource Information Network [GRIN]; data available online). ${ }^{7}$ In the present study, the status and term native was allocated to species native to Germany in the strict sense (Trifolium repens, Trifolium pratense, Origanum vulgare), German

\footnotetext{
${ }^{7}$ https://www.grin-global.org/
} 
archaeophytes (Artemisia absinthium, Erysimum cheiri) and species that are native only to other parts of Europe but that also occur in Germany (Linaria purpurea, Tragopogon porrifolius, Lobularia maritima). German and New Zealand seeds were either purchased from commercial seed companies and botanical gardens or provided by the Lincoln University (New Zealand seeds of Trifolium pratense and Trifolium repens), and jointly cultivated in both common gardens (Table 1 and Appendix S1 for species list and seed origin information). All seeds originated either from established ex situ outdoor populations or from propagation areas of regional genotypes to ensure that the plants had experienced growth under natural solar radiation and were able to adapt to ambient conditions. All seeds were germinated in the greenhouse (either in New Zealand or in Germany) under controlled conditions in seedling trays. In the following, we distinguish seeds of local populations (i.e., German populations tested in Germany, New Zealand populations tested in New Zealand) and seeds of foreign populations (i.e., German populations tested in New Zealand and New Zealand populations tested in Germany). Individuals were transferred to $2-\mathrm{L}$ pots about six to eight weeks after sowing. Legal import regulations precluded the use of identical substrate and thereby the use of standardized soils across experiments. We therefore made use of local common usage substrates at the two gardens: New Zealand substrate was based on bark and pumice, supplemented with horticultural lime and slow-release fertilizer $\left(3 \mathrm{~kg} / \mathrm{m}^{3}\right)$. In Germany, we used a peat substrate with natural clay, supplemented with directly soluble mineral nutrients and slow-release fertilizer $\left(3 \mathrm{~kg} / \mathrm{m}^{3}\right)$. Plants were assigned to the experimental settings when they were 10 weeks old.

In both common gardens, the plants were exposed to three UV treatments, including (1) full exposure to ambient, natural UV-A, and UV-B radiation, (2) exclusion of UV-B while allowing natural UV-A, and (3) total exclusion of both UV-A and UV-B wavelengths (Fig. 1). These three UV environments allowed for the comparison of ambient solar radiation conditions and two artificial UV environments to derive the ecologically inseparable effects of UV-A and UV-B, such as the not fully understood UV-A mitigation effect (Verdaguer et al. 2017). To apply these UV treatments to the plants, we used in both common gardens each six UV cabinets (Appendix S2) per UV treatment, equipped with acrylic (PLEXIGLAS GS 2458 clear; Evonik Industries AG, Essen, Germany), polyethylene terephthalate glycol (Polycasa PETG clear B1; thyssenkrupp Plastics GmbH, Essen, Germany) and polycarbonate sheets (Makrolon GP clear 099; thyssenkrupp Plastics $\mathrm{GmbH}$ ), respectively. One individual of each species was randomly assigned and positioned in each UV cabinet, resulting in six replicates per species and treatment (totaling 18 individuals per species). Each three of the six replicates per species and treatment originated from either a local or a foreign seed source, resulting in three replicates per species, treatment and origin. In total, six local and foreign individuals of each species were randomly allocated to the six UV cabinets representing one UV treatment level. In consequence, each UV cabinet contained only one individual per species (either local or foreign), but, in total, eight individuals of different species and of randomized mixed origin. In order to counteract potential undesired shading effects of neighboring plants, we randomly repositioned all plants within the UV cabinets every other week during the experimental runtime.

To characterize climate conditions at the experimental sites, we obtained official climate data for Germany from the Climate Data Centre of Deutscher Wetterdienst (DWD; data available online) and the Federal Office for Radiation Protection (BfS; data available online). ${ }^{8} 9 \mathrm{New}$ Zealand climate data was obtained from the National Climate Database (NIWA; data available online) and the UV Atlas Version 2.2 (Bodeker et al. 2006). ${ }^{10}$ Both experiments had comparable temperature conditions during their respective runtime with a maximum temperature of about $30^{\circ} \mathrm{C}$ but a slightly lower minimum temperature in New Zealand during that period (DEU, $4.1^{\circ} \mathrm{C}$; NZL, $2.1^{\circ} \mathrm{C}$ ). Dependent on species-specific experimental duration (see Data collection), plants experienced in total up to 495 sunshine hours in Germany and $760 \mathrm{~h}$ of sun in New Zealand, resulting on average in one sunshine hour by experimental day more in New Zealand than in Germany. The mean daily global radiation dose was about twice as high in the New Zealand common garden compared to the common garden in Germany. UV-B intensities showed a significant difference between both sites with 2.5 times higher daily UV-B dose in New Zealand and, consequently, a maximum UV-B radiation sum of $3,454 \mathrm{~kJ} / \mathrm{m}^{2}$ compared to $974 \mathrm{~kJ} / \mathrm{m}^{2}$ in Germany (Appendix S3). All information on climate data including the specification of data source and the distance of the respective measuring stations to the common garden locations is listed in the appendix (Appendix S3).

\section{Data collection}

To address plant responses to UV-B with respect to photoprotection ability and individual performance, such as fitness-relevant traits, we determined responses at different organizational levels ranging from leaf traits, through whole-plant responses, to measures of reproduction. All 287 individuals were harvested species-wise depending on the species-specific developmental climax, i.e., the moment of maximum biomass production prior to seasonal wilting of inflorescences or leaves (see Table 1 for species-specific experimental duration). Accordingly, the species remained for different periods in the common gardens ranging from 73 to $107 \mathrm{~d}$ in the

\footnotetext{
${ }^{8} \mathrm{http} / / / \mathrm{www} . \mathrm{dwd} . \mathrm{de} / \mathrm{EN} / \mathrm{climate}$ environment/cdc/cdc.html

${ }^{9}$ http://www.bfs.de

${ }^{10} \mathrm{https} / / /$ cliflo.niwa.co.nz/
} 
New Zealand experiment and from 73 to $77 \mathrm{~d}$ in the German experiment. Persistently stable late summer climatic conditions in New Zealand in March 2015 allowed for an extended experimental runtime, whereas harsher climatic conditions in early October 2015 in Germany resulted in an earlier termination of the common garden experiment due to an earlier induced senescence.

Especially leaf traits, such as specific leaf area (SLA) and leaf dry matter content (LDMC) have proven to be strongly sensitive to UV radiation (Robson et al. 2015). Therefore, at the harvest day, we determined maximum leaf length of all individuals, sampled fresh material of several fully developed and healthy leaves in a standardized way and determined leaf area with WinFOLIA 2015 software (Regent Instruments Inc., Québec, Canada). For each individual, the functional leaf traits SLA and LDMC were subsequently calculated. Based on freeze-dried leaf material, we used elemental analyzer measurements (Euro EA 3000; HEKAtech GmbH, Wegberg, Germany) for determination of total foliar carbon content and nitrogen content, as in previous studies a wider $\mathrm{C}: \mathrm{N}$ ratio turned out to be an indicator for stressful environmental conditions (Chen et al. 2015). Furthermore, secondary metabolites have shown to be a good indicator for high UV levels at lower organizational levels (Kataria et al. 2014). Thus, to determine the concentration of total phenolics, $0.01 \mathrm{mg}$ homogenized leaf material was extracted twofold in $80 \%$ methanol. After centrifugation, the absorption of the supernatants was measured at $765 \mathrm{~nm}$ in a plate reader after addition of Folin-Ciocalteu reagent (following Austel et al. 2016). A concentration series of gallic acid was measured in parallel and the total phenolics concentration per sample was calculated as gallic acid equivalent.

In order to assess the reproductive effort of all flowering individuals, we counted the number of inflorescences. As characteristic growth traits that may be affected by UV radiation, plant height and maximum plant expansion were determined at the harvest day. Aboveground and belowground biomass were separated, dried at $80^{\circ} \mathrm{C}$ for $48 \mathrm{~h}$ and subsequently weighed. Finally, the root: shoot ratio was calculated for each individual as allocation variable.

\section{Statistical analysis}

As we were more interested in identifying overall effects across the species of the entire species pool rather than in particular species-specific differences, all data were standardized by z-transformation within species and the resulting $z$ scores were used for subsequent analysis (according to Haider et al. 2012). The standardization of absolute changes in response variables (raw scores) results in a comparable expression of the within-species response to different environments. The $z$ scores represent the number of species-specific standard deviations and, thus, allow accounting for absolute species-inherent differences (see Appendix S4 for species-specific variance in raw data). For data analysis, linear mixed models were applied in $\mathrm{R}$ (Version 3.2.3; R Core Team 2017) using the function lmer (packages lme4 [Bates et al. 2015], lmerTest [Kuznetsova et al. 2016]) and type 3 sum of squares. We tested for effects of experimental site, addressed as range in the following (native DEU, exotic NZL), UV treatment (-UV-A|-UV-B, +UV-A|-UV-B, +UV-A|+UV-B), and origin (DEU, NZL), as well as all their interactions. We additionally included specific experimental duration of individuals dependent on species and experimental site as a covariate. Furthermore, we defined three nested random effects (according to Zuur et al. [2009]) to correct for the block effect of UV cabinets, that did not display true replicates of each other, and included cabinet : range, cabinet : UV treatment, and cabinet : origin. To correct for potential species identity effects in the multispecies approach, e.g., due to functional trait differences between species, origin : species and UV treatment : species were additionally included as random effects in the model. Separate analyses on initial plant height and leaf numbers revealed no significant difference between treatments or origins prior to the experimental UV treatment (data not shown).

\section{RESULTS}

For most of the variables tested, we found significant range effects and range $\times$ origin interactions, indicating a different outcome due to the location of the common gardens, whereas main effects of origin and UV treatments were of importance only for selected variables (Table 2).

\section{Range effects}

In the exotic range in New Zealand, plants had generally higher values in total biomass, plant height, and number of inflorescences than in the native range in Germany (Figs. 2a, 3b, Table 2). Leaves of plants grown in the exotic range were characterized by a wider $\mathrm{C}: \mathrm{N}$ ratio, as well as a higher LDMC and total phenolic concentrations compared to plants grown in the native range (Figs. 2e, g, 3a, Table 3). In contrast, plants grew significantly larger leaves with higher maximum leaf length in the native range common garden (Fig. 2d, Table 3).

\section{Effects of UV treatment}

Across all species in both common gardens, UV treatment effects were clearly expressed in maximum plant expansion and phenolic concentrations (Tables 2, 3; Appendix S5). Maximum plant expansion was significantly reduced under full solar UV-B radiation compared to UV filter treatments with a tendency to a stronger reduction in New Zealand individuals (Fig. 4b, Table 2). Leaf phenolic concentrations were significantly increased in the presence of UV (Fig. 3a, Table 3). Although not displaying overall significance, total biomass and maximum leaf length tended to be lower under 
TABLE 2. Fixed-effect results of the mixed model analysis of growth and reproduction traits across both common garden experiments (range).

\begin{tabular}{|c|c|c|c|c|c|c|c|c|c|c|c|c|c|c|c|c|}
\hline \multirow[b]{2}{*}{ Source } & \multirow[b]{2}{*}{$\mathrm{df}_{\mathrm{N}}$} & \multicolumn{3}{|c|}{ Total biomass } & \multicolumn{3}{|c|}{ Plant height } & \multicolumn{3}{|c|}{ Max. plant expansion } & \multicolumn{3}{|c|}{ Root: shoot ratio } & \multicolumn{3}{|c|}{ No. inflorescences } \\
\hline & & $\mathrm{df}_{\mathrm{D}}$ & $F$ & $P$ & $\mathrm{df}_{\mathrm{D}}$ & $F$ & $P$ & $\mathrm{df}_{\mathrm{D}}$ & $F$ & $P$ & $\mathrm{df}_{\mathrm{D}}$ & $F$ & $P$ & $\mathrm{df}_{\mathrm{D}}$ & $F$ & $P$ \\
\hline Range & 1 & 148.7 & 19.418 & $<0.001 * * *$ & 49.8 & 40.081 & $<0.001 * * *$ & 257.9 & 0.321 & 0.572 & 259.6 & 1.679 & 0.196 & 191.4 & 47.768 & $<0.001 * * *$ \\
\hline UV & 2 & 27.8 & 2.555 & 0.096 & 19.0 & 1.327 & 0.289 & 113.8 & 3.120 & $0.048 *$ & 99.9 & 0.310 & 0.734 & 11.5 & 0.017 & 0.984 \\
\hline Origin & 1 & 13.3 & 0.784 & 0.392 & 13.9 & 0.114 & 0.741 & 14.5 & 0.080 & 0.781 & 14.4 & 0.027 & 0.871 & 9.0 & 0.140 & 0.717 \\
\hline $\begin{array}{l}\text { Experiment } \\
\text { duration }\end{array}$ & 1 & 86.4 & 0.114 & 0.736 & 243.7 & 38.013 & $<0.001 * * *$ & 199.7 & 15.439 & $<0.001 * * *$ & 209.0 & 5.564 & $0.019 *$ & 195.6 & 17.070 & $<0.001 * * *$ \\
\hline Range $\times$ UV & 2 & 93.8 & 1.654 & 0.197 & 18.0 & 0.744 & 0.489 & 115.9 & 0.753 & 0.473 & 103.3 & 1.421 & 0.246 & 181.1 & 6.182 & $0.003^{* *}$ \\
\hline Range $\times$ origin & 1 & 266.4 & 9.104 & $0.003^{* *}$ & 257.5 & 0.357 & 0.551 & 254.3 & 4.628 & $0.032 *$ & 253.8 & 5.772 & $0.017^{*}$ & 184.4 & 0.959 & 0.329 \\
\hline $\mathrm{UV} \times$ origin & 2 & 257.2 & 0.725 & 0.485 & 254.7 & 0.587 & 0.557 & 113.6 & 2.635 & 0.076 & 99.6 & 0.062 & 0.940 & 185.9 & 0.787 & 0.457 \\
\hline $\begin{array}{l}\text { Range } \times \\
\text { UV } \times \text { origin }\end{array}$ & 2 & 256.9 & 0.380 & 0.684 & 254.7 & 0.147 & 0.863 & 115.8 & 0.116 & 0.891 & 103.3 & 0.215 & 0.807 & 185.9 & 0.428 & 0.653 \\
\hline
\end{tabular}

Notes: UV (ultraviolet) depicts the effect of additional UV treatments, origin refers to the effect of German vs. New Zealand provenance. Harvest traits were standardized by $z$-transformation within species. Degrees of freedom $\left(\mathrm{df}_{\mathrm{N}}=\right.$ numerator, $_{\mathrm{df}} \mathrm{D}=\mathrm{de}-$ nominator), $F$ statistics $(F)$, and significance values $(P)$ are provided. Values in boldface type indicate significant $P$ values $\left({ }^{*} P<0.05 ; * * P<0.01 ; * * P<0.001\right)$ and values in italic typeface indicate marginal effects. $(P<0.1)$.

UV-B exposition (Fig. 4a, c, Tables 2, 3). In the German common garden, the number of inflorescences was highest in environments with total UV exclusion and lowest in presence of UV-A but absence of UV-B. The trend across UV environments was the opposite for plants grown in the exotic range common garden, while the number of inflorescences was generally higher when plants were grown in New Zealand (Fig. 3b, Table 2).

\section{Differences between origins}

Across all species, SLA was significantly higher in individuals from New Zealand populations (Figs. 2f, 4d). This difference was accompanied by a significant range $\times$ origin interaction, displaying increased SLA for New Zealand individuals when grown in the German common garden, whereas the range had no significant effect on the SLA of German individuals (Fig. 2f, Table 3). In addition, there were numerous interaction effects of range and origin across all groups of variables indicating increased responses in their respective home common garden: the local individuals concordantly showed higher total biomass as well as maximum expansion in the German and in the New Zealand common garden, compared to the respective foreign individuals (Fig. 2a, c, Table 2). Significant origin $\times$ range interaction effects indicate a narrow root:shoot ratio of New Zealand plants in their home range and a wider root: shoot ratio in plants grown in the German common garden, whereas German individuals did not show substantially modified allocation patterns across ranges (Fig. 2b, Table 2). While in the exotic range common garden, maximum leaf length was at a similar level for plants of both local and foreign origins, plants of local origins responded with much longer leaves than those of foreign origins when tested in the native range common garden, thus displaying a significant range $\times$ origin interaction (Fig. 2d, Table 3). Also for LDMC and the $\mathrm{C}: \mathrm{N}$ ratio plants of both origins displayed similarly high values in the exotic range common garden but tended to diverge in the native range only (Fig. 2e, g, Table 3 ).
We did not find any significant origin $\times$ treatment interaction effects pointing at differentiated origin-specific responses to UV radiation, although plants of both origins at least tended to respond differently to the UV treatments in terms of maximum plant expansion and SLA area (Fig. 4b, d, Table 3).

\section{Discussion}

To test for the general effects of UV-B radiation on plants and for the impact of different natural UV-B radiation intensities in Germany and New Zealand, we specifically evaluated the significant effects of the applied UV treatments and respective UV treatment $\times$ experimental site interaction effects. We furthermore aimed to identify origin differentiation between local and foreign individuals in both common garden experiments according to the second hypothesis by interpretation of origin effects and interaction effects of origin with experimental sites. Finally, we wanted to assess, whether there is even evidence of origin differentiation caused by local adaptation to UV-B radiation regimes in high-UV-B environments as stated in the third hypothesis and supported by UV treatment $\times$ origin interaction effects.

Across all variables studied, leaf traits consistently displayed the strongest responses to most of the predictors of range, origin and UV. In contrast, allocation and growth traits were more triggered by range and range $\times$ origin interactions, while the number of inflorescences was responsive to range $\times \mathrm{UV}$ treatment interactions only.

\section{UV effects on plants}

The reduction of maximum plant expansion, as well as an overall increase of leaf phenolic concentrations due to solar UV radiation across both ranges confirms previously observed changes in plant morphology and leaf compounds in response to UV radiation (Suchar and Robberecht 2014, Coffey et al. 2017). However, it is most 

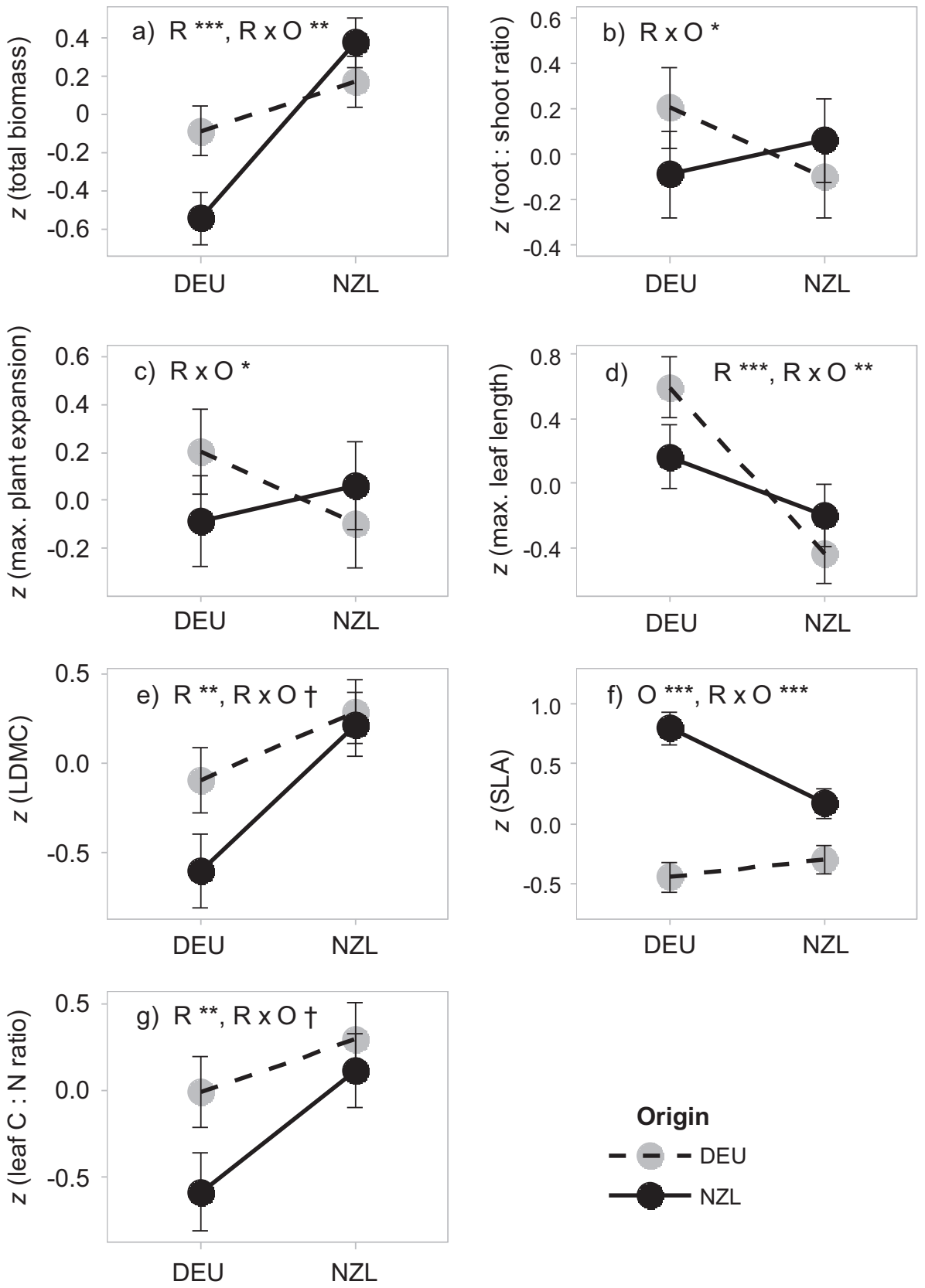

FIG. 2. (a-g) Effects of origins across common gardens. Reaction norms (predicted means \pm SE) of German (gray, dashed line) and New Zealand (black, solid line) populations across the native (DEU) and exotic range (NZL) for (a) total biomass $(n=287)$, (b) root: shoot ratio $(n=284)$, (c) maximum plant expansion $(n=286)$, (d) maximum leaf length $(n=287)$, (e) leaf dry matter content $(n=264)$, (f) specific leaf area $(n=264)$ and (g) leaf carbon: nitrogen ratio $(n=248$ of 7 species). The number of species included was 8 if not stated differently. Significance levels $\left(\dagger P<0.1,{ }^{*} P<0.05, * * P<0.01, * * * P<0.001\right)$ are given for effects of range $(R)$, origin $(O)$ and their interaction $(R \times O)$.

notable that these effects were consistent across multiple species, origins and in different regions. In line with these effects, also total biomass and maximum leaf length tended to be reduced by exposure to full solar wavelengths including all UV components. While phenolics are known to be easily induced by low UV-B doses, only higher doses additionally trigger a more generic stress response that may involve changes in cell cycle activity and result in biomass/leaf area loss (Robson et al. 2015). This difference in trait responses at different organizational levels ranging from accumulation of a class of compounds within plant cells up to whole-plant responses is 


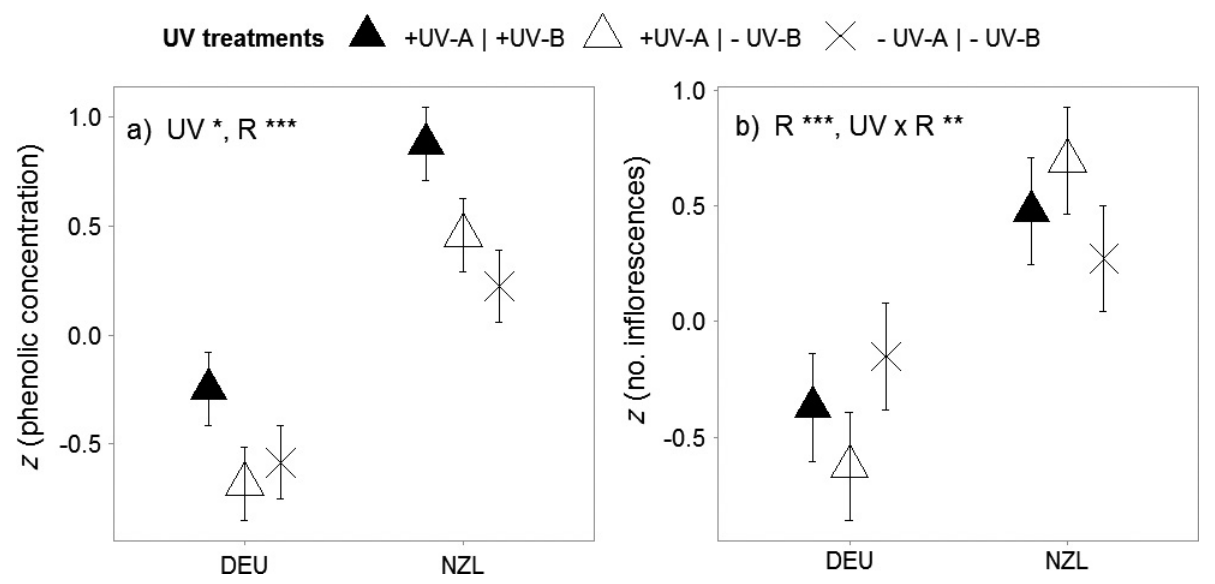

FIG. 3. (a, b) Effects of ultraviolet (UV) treatments in common gardens. Predicted values \pm SE of (a) phenolic concentration ( $n=247$ of 7 species) and (b) the number of inflorescences ( $n=215$ of 6 species) across the native (DEU) and exotic range (NZL) for the UV treatments (+UV-A|+UV-B, +UV-A|-UV-B, $-\mathrm{UV}-\mathrm{A} \mid-\mathrm{UV}-\mathrm{B})$. Significance levels $(* P<0.05, \quad * * P<0.01$, $* * * P<0.001)$ are given for effects of range $(\mathrm{R}), \mathrm{UV}$ treatments $(\mathrm{UV})$ and their interaction $(\mathrm{UV} \times \mathrm{R})$.

partly reflected in the patterns and in the strength of significance effects encountered in our data set. In contrast to our first hypothesis, the absence of range $\times$ UV treatment interaction effects in leaf and growth traits indicates that UV radiation affected plants similarly in both ranges, despite significant differences in ambient UV intensities between the two experimental sites (Appendix S3). Nevertheless, shorter leaves with higher LDMC and narrower $\mathrm{C}: \mathrm{N}$ ratio, as well as clearly increased levels of phenolic concentration in plants grown in the New Zealand common garden hint at less favorable environmental conditions as, e.g., caused by higher UV radiation intensities in the exotic range (Bacelar et al. 2015, Robson et al. 2015). However, our results provide evidence for differences in plant responses between the common garden experiments even in the full UV exclosure treatment and, therefore, point at the existence of further local factors that affect plant phenotypes in both ranges in addition to UV radiation. Accordingly, enhanced productivity as expressed in increased plant height and higher total biomass in the exotic range may also be induced by co-varying conditions that are more beneficial in the New Zealand common garden than in the German one, e.g., higher global radiation intensity (as indicated, e.g., by higher global total radiation and higher number of total sun hours in NZ, see Appendix S3), longer day length due to shorter distance to the equator, and consequently higher photosynthesis. In line with these thoughts, in the exotic range common garden only, highest maximum leaf length and number of inflorescences was observed under UV-A exposure in combination with simultaneous UV-B exclosure, pointing at the potentially facilitative effects of high UV-A radiation intensities (Verdaguer et al. 2017) as they might exclusively occur in the southern hemisphere. According to our first hypothesis, plant growth and development were significantly affected by natural UV-B radiation but the effect appeared to be predominantly independent of experimental site. The observed UV effects on plant physiology and morphology generally emphasize the fundamental importance of this environmental factor for plant growth and development and indicate that differences in both UV-A and UV-B intensities may be involved in explaining differences in performance in plant invasions.

\section{Genetic differentiation and local adaptation in the exotic range}

According to the second hypothesis, we expected an origin-dependent differentiation in consequence of divergent selection pressures in the two ranges that might hint at local adaptation. Specific leaf area was the only trait to display an overall difference between origins consistently across all UV levels or ranges tested, with smaller SLA in German than in New Zealand plants. This response obviously suggests genetically fixed differentiation in SLA across different environments as result of a divergent natural selection in the native and exotic range (see also Mozdzer and Zieman 2010, Leishman et al. 2014). Specific leaf area of New Zealand individuals was furthermore strongly increased when plants were grown in the native range, possibly indicating a release from high-energy wavelengths and hence a lack of necessity for leaf thickening to provide photoprotection. Consistent with SLA responses in plants from New Zealand, there tended to be generally a lower LDMC and a narrower $\mathrm{C}: \mathrm{N}$ ratio that further decreased when plants were grown in the native range, whereas German individuals did not substantially modify their leaf traits between ranges ( $p_{\text {origin:range }}<0.1$ ). The development of thinner leaves with reduced LDMC is a syndrome of lower-cost products and might be a useful strategy for New Zealand individuals under elevated UV-B radiation, especially if DNA photorepair works well and epidermal 
TABLE 3. Fixed-effect results of the mixed model analysis of leaf traits across both common garden experiments (range).

\begin{tabular}{|c|c|c|c|c|c|c|c|c|c|c|c|c|c|c|c|c|}
\hline \multirow[b]{2}{*}{ Source } & \multirow[b]{2}{*}{$\mathrm{df}_{\mathrm{N}}$} & \multicolumn{3}{|c|}{ Maximum leaf length } & \multicolumn{3}{|c|}{ Specific leaf area } & \multicolumn{3}{|c|}{ Leaf dry matter content } & \multicolumn{3}{|c|}{$\mathrm{C}: \mathrm{N}$} & \multicolumn{3}{|c|}{ Phenolic concentration } \\
\hline & & $\mathrm{df}_{\mathrm{D}}$ & $F$ & $P$ & $\mathrm{df}_{\mathrm{D}}$ & $F$ & $P$ & $\mathrm{df}_{\mathrm{D}}$ & $F$ & $P$ & $\mathrm{df}_{\mathrm{D}}$ & $F$ & $P$ & $\mathrm{df}_{\mathrm{D}}$ & $F$ & $P$ \\
\hline Range & 1 & 258.0 & 28.180 & $<0.001 * * *$ & 46.0 & 2.669 & 0.109 & 58.6 & 11.096 & $0.002^{* *}$ & 205.1 & 8.808 & $0.003^{* *}$ & 63.0 & 48.702 & $<0.001 * * *$ \\
\hline UV & 2 & 16.9 & 3.239 & 0.064 & 30.2 & 0.292 & 0.749 & 29.4 & 0.233 & 0.794 & 89.7 & 0.205 & 0.815 & 11.9 & 4.805 & $0.030^{*}$ \\
\hline Origin & 1 & 13.0 & 0.158 & 0.697 & 14.8 & 57.949 & $<0.001^{* * *}$ & 12.3 & 2.050 & 0.177 & 10.6 & 2.075 & 0.179 & 10.3 & 0.164 & 0.693 \\
\hline $\begin{array}{l}\text { Experiment } \\
\text { duration }\end{array}$ & 1 & 233.0 & 0.304 & 0.582 & 49.3 & 0.127 & 0.723 & 94.8 & 6.141 & $0.015^{*}$ & 155.3 & 6.202 & $0.014 *$ & 84.1 & 8.277 & $0.005^{* *}$ \\
\hline Range $\times$ UV & 2 & 100.5 & 0.763 & 0.469 & 30.2 & 0.649 & 0.529 & 29.4 & 0.046 & 0.955 & 93.6 & 0.419 & 0.659 & 91.8 & 0.811 & 0.447 \\
\hline $\begin{array}{c}\text { Range } \times \\
\text { origin }\end{array}$ & 1 & 239.6 & 10.936 & $0.001 * *$ & 245.5 & 12.576 & $<0.001 * * *$ & 245.7 & 3.541 & 0.061 & 222.1 & 2.810 & 0.095 & 213.8 & 2.698 & 0.102 \\
\hline $\mathrm{UV} \times$ origin & 2 & 98.8 & 0.385 & 0.681 & 236.6 & 2.758 & 0.065 & 229.6 & 0.477 & 0.621 & 89.7 & 1.989 & 0.143 & 50.8 & 1.5180 .229 & \\
\hline $\begin{array}{l}\text { Range } \times \\
\text { UV } \times \text { origin }\end{array}$ & 2 & 102.2 & 1.724 & 0.183 & 236.7 & 0.360 & 0.698 & 229.6 & 1.345 & 0.263 & 93.6 & 0.114 & 0.893 & 53.8 & 0.056 & 0.946 \\
\hline
\end{tabular}

Notes: UV depicts the effect of additional UV treatments, origin refers to the effect of German vs. New Zealand provenance. Harvest traits were standardized by $z$-transformation within species. Degrees of freedom $\left(\mathrm{df}_{\mathrm{N}}=\right.$ numerator, $\left.\mathrm{df}_{\mathrm{D}}=\mathrm{denominator}\right)$, $F$ statistics $(F)$, and significance values $(P)$ are provided. Values in boldface indicate significant $P$ values $(* P<0.05, * * P<0.01$, $* * * P<0.001)$ and values in italic typeface indicate marginal effects. $(P<0.1)$.

absorbance by secondary metabolites is simultaneously enhanced (Feng et al. 2008, Suchar and Robberecht 2014). This would be worth to be tested in a future study, as following the third hypothesis, New Zealand individuals were expected to evolve such specific adaptations to higher UV-B intensities in the exotic range. In the present study, we were able to show patterns of local adaptation following the "local vs. foreign" criterion (Kawecki and Ebert 2004) by crossed origin $\times$ range interactions for several variables of productivity (total biomass), biomass allocation (root: shoot ratio), plant architecture (maximum plant expansion), and leaf traits (leaf length). For these variables, the local individuals reached higher performance in their respective home common gardens, although the "home vs. away" criterion (Kawecki and Ebert 2004) was not met simultaneously in most cases, i.e., performance across ranges might still result in a better performance away from home (Leimu and Fischer 2008). Thus, we found evidence for adaptation of populations to local environmental conditions, resulting in more productive individuals with enhanced competitive ability due to higher investment in aboveground biomass and consequently enhanced space occupation. However, while the discussed local adaptation might be associated with differences in UV intensities between ranges, it may additionally induced by other differences in local selection pressures, e.g., herbivory, pathogens, or macroclimatic factors (Kuhlmann and Müller 2009, Escobar-Bravo et al. 2017).

Although the observed origin differentiation was not clearly attributable to selection by high UV-B intensities (contrary to our third hypothesis), we found a crossed reaction norm of German and New Zealand individuals for maximum plant expansion along the three UV treatments $\left(p_{\text {origin:treatment }}<0.1\right.$ ). Under full solar UV radiation, individuals from the exotic range were characterized by smaller maximum plant expansion compared to the German individuals, whereas the relationship was reversed under total exclusion of UV wavelength. The reduction in size could be either interpreted as an immediate consequence of UV-Binduced growth inhibition or, as an alternative, might indicate a morphological adaptation of New Zealand individuals to high UV-B radiation intensities in New Zealand, as photodamage might be efficiently prevented by downsizing the UV-B-exposed plant surface area. To elucidate the causal dependency here, one would have to additionally compare fitness traits, e.g., investment in reproductive biomass or number of fertile seeds, and thus test whether fitness is also reduced or being maintained. In contrast to previous studies (Robson et al. 2015, Fraser et al. 2017), German individuals did not show any plant architecture change in response to UV radiation that might hint at a lack of necessity regarding strong photoprotection in their home range. However, both strategies might be a consequence of local selection due to ambient UV-B radiation intensities in the respective home range, as different UV response patterns of German and New Zealand individuals across the UV treatments clearly displayed differentiation of origins within species that is less likely to be affected by other local environmental factors.

\section{Phenotypic plasticity}

The various significant interaction effects of origin with range in the present study, but only few general differences between German and New Zealand individuals hint at the importance of trait plasticity, rather than genetic differentiation due to divergent natural selection in the native and exotic range.

The comparison of reaction norm slopes in traits from plants of both origins among different environments allows assessing the role of plasticity by traits (Schlichting and Pigliucci 1998, Kawecki and Ebert 2004, Chun et al. 2007). In the present study, several traits showed notably steeper reaction norm slopes of plants from New Zealand in both common gardens (e.g., SLA, LDMC, C:N ratio) and therefore New Zealand individuals might be considered more plastic in functional leaf traits, which play a major role in photoprotection 


\section{Origin -- $-\mathrm{DEU}-\mathrm{NZL}$}
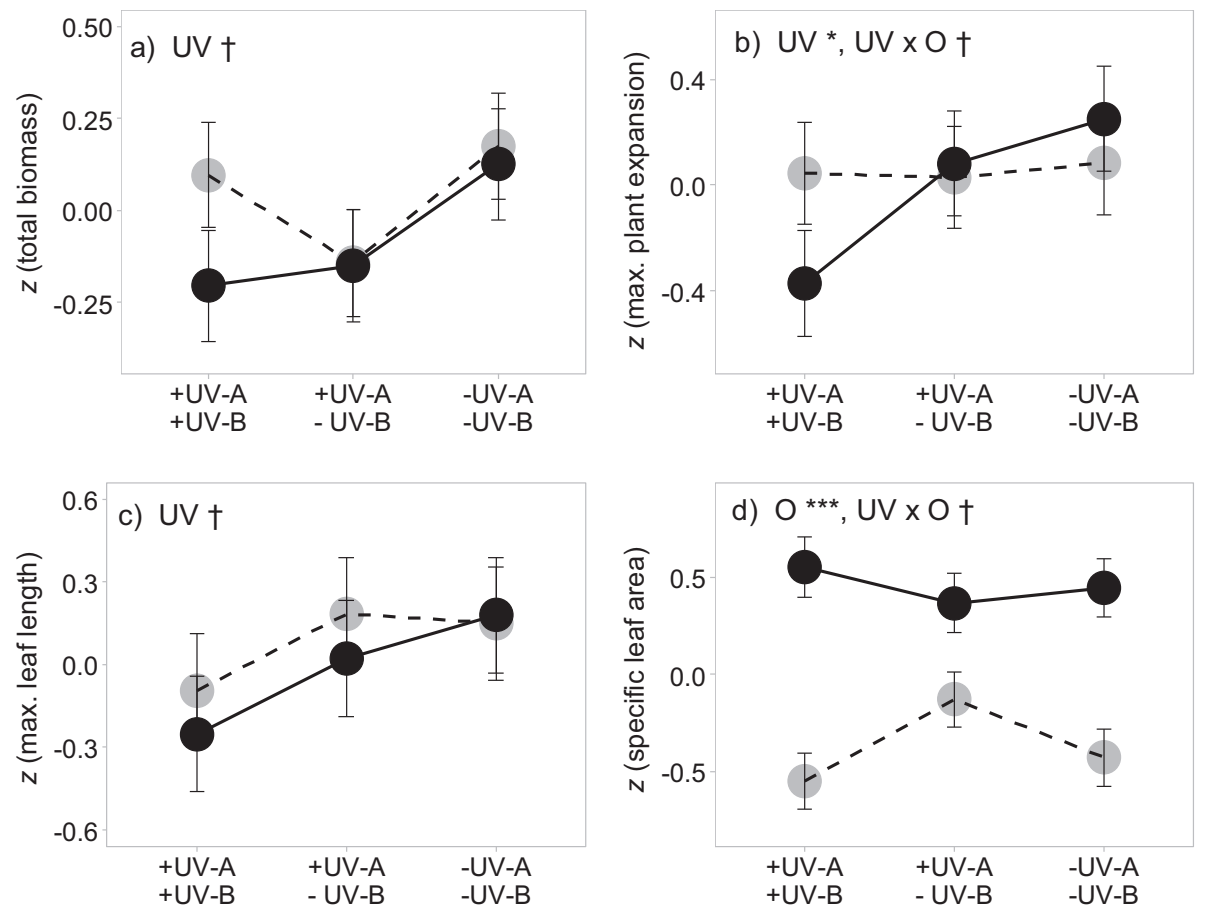

FIG. 4. (a-d) Effects of origin across ultraviolet (UV) treatments. Reaction norms (predicted means \pm SE) of German (gray, dashed line) and New Zealand (black, solid line) populations across the UV treatments (+UV-A $|+\mathrm{UV}-\mathrm{B},+\mathrm{UV}-\mathrm{A}|-\mathrm{UV}-\mathrm{B},-\mathrm{UV}-\mathrm{A} \mid-$ UV-B) for (a) total biomass $(n=287)$, (b) maximum plant expansion $(n=286)$, (c) maximum leaf length $(n=287)$ and (d) specific leaf area $(n=264)$. The number of species included was 8 if not stated differently. Significance levels $(\dagger P<0.1, * P<0.05$, $* * * P<0.001)$ are given for effects of $\mathrm{UV}$ treatments $(\mathrm{UV})$, origin $(\mathrm{O})$ and their interaction $(\mathrm{UV} \times \mathrm{O})$.

measures of plants and most likely facilitate a higher UV-B tolerance. Accordingly, during colonization, exotic genotypes might also have been selected for high phenotypic plasticity in the exotic range New Zealand (Oplaat and Verhoeven 2015, Turner et al. 2015). Resulting enhanced UV-B tolerance furthermore explains higher plasticity in terms of a stronger increase in productivity (total biomass) in the exotic range. High plasticity of genotypes in traits across different environments ("general-purpose-genotype" according to Parker et al. 2003) has been frequently considered beneficial in the context of colonization of new habitats (Richards et al. 2006, Hulme 2008). It might display a regulatory response of plants to increase their tolerance to changing conditions and therefore adjust their phenotype to sitespecific requirements ("adaptive plasticity" according to Donohue et al. 2000, Ghalambor et al. 2007). On the other hand, phenotypic plasticity could just represent the plant's sensitivity to environmental factors and, thus, moves individuals away from the optimal phenotype ("non-adaptive plasticity" according to van Kleunen and Fischer 2005, Ghalambor et al. 2007). In the present study, enhanced UV-B tolerance combined with a higher performance under moderate or even demanding radiation conditions in high-UV-B environments rather support the concept of "adaptive plasticity" according to
Ghalambor et al. (2007) as a valuable strategy to cope with high UV-B intensities.

In the present study, German individuals were found to be more plastic in leaf length and phenolic concentration, i.e., in variables that are more likely to display photodamage responses to higher UV-B intensities and therefore hint at insufficient physiological photoprotection. One of the rare studies that compared the photoprotective strategies of an invasive species and a coexisting native species (Fenollosa et al. 2017), described an interesting pattern: whereas the native species showed a "saving strategy" by restricting physiological variation to the minimum and only adapted morphologically, the invasive species used an "all-in strategy" by stimulation of multiple photoprotection mechanisms. The authors assume that an all-in strategy would be especially suitable in environments with less predictable climatic conditions. Based on this finding, New Zealand individuals in the present study might have changed their photoprotective strategy to higher physiological plasticity during colonization, similarly as described for an invasive species by Fenollosa et al. (2017).

However, the relative importance of phenotypic plasticity to local adaptation is often assumed to decrease in the course of the colonization process (Dietz and 
Edwards 2006, Si et al. 2014, Zenni et al. 2014, Lamarque et al. 2015), and may largely depend also on the cost of plasticity, the mean variance and predictability of the new environment and on whether the novel range actually requires a new optimal phenotype (Lande 2015). Evolution of greater phenotypic plasticity during plant invasions is generally assumed to be costly for species and even more likely constrained in stressful environments, whereas any relief from stressful factors (e.g., enemy release) in the exotic range may facilitate evolution of phenotypic plasticity (Huang et al. 2015). Regarding UV-B, Suchar and Robberecht $(2014,2016)$ did not find an indication for a direct link between cost for epidermal UV-B absorbing compounds and inhibition of growth. Accordingly, investment in photoprotection by secondary metabolites can be considered a very efficient plant response in high-UV-B environments and might enable evolution of phenotypic plasticity.

\section{Conclusions}

In the present multispecies study, we found evidence for population differentiation of German and New Zealand individuals that allows for some generalization: recent adaptations consequently contributed to better performance of local individuals compared to foreign individuals in both common garden experiments in the native and exotic range, respectively. The observed local adaptation during colonization of highUV-B environments did not reveal to be directly attributable to selection by UV-B radiation, but might rather be the consequence of selection for genotypes with high phenotypic plasticity. In the present study, the resulting origin differentiation became even evident in response to different UV-B regimes. The importance of well-adapted photoprotection abilities in high-UV-B environments should be more explicitly investigated in future studies, particularly, including long-term approaches to assess plant fitness across generations. In general, the observed combined mechanisms of local adaptation and phenotypic plasticity might enable exotic species to spread farther than it would be expected by their native distribution even into high-UV-B environments.

\section{Acknowledgments}

We thank the Timaru Botanic Gardens and the Southland Seed Savers Network for provision of seeds from New Zealand populations. The seed import to New Zealand could be managed via the International Plant Exchange Network (IPEN), handled by E. Grimm (Botanical Garden of Martin Luther University Halle-Wittenberg) and S. Molloy (Christchurch Botanic Gardens). M. Korver (Manaaki Whenua-Landcare Research) realized leaf sample shipping to Germany. We thank L.-M. Beckmann, N. Bieker, K. Borisova, R. Franke, C. Küver, T. Martens, S. Merseburger, and L. Watermann for helping with plant monitoring and harvest and M. Bahns (Kiel University) and S. Stilwell (Lincoln University) for technical support. The study was financially supported by doctoral scholarships from the State Postgraduate Scholarship Programme of SaxonyAnhalt and the FAZIT foundation, as well as a DAAD (German Academic Exchange Service) travel grant awarded to $\mathrm{M}$. Hock.

\section{Literature Cited}

Allan Herbarium. 2000. Ngā Tipu o Aotearoa, New Zealand Plant Names Database. Landcare Research, New Zealand. http://nzflora.landcareresearch.co.nz/

Austel, N., E. J. Eilers, T. Meiners, and M. Hilker. 2016. Elm leaves 'warned' by insect egg deposition reduce survival of hatching larvae by a shift in their quantitative leaf metabolite pattern. Plant, Cell \& Environment 39:366-376.

Bacelar, E., J. Moutinho-Pereira, H. Ferreira, and C. Correia. 2015. Enhanced ultraviolet-B radiation affect growth, yield and physiological processes on triticale plants. Procedia Environmental Sciences 29:219-220.

Barnes, P. W., M. A. Tobler, K. Keefover-Ring, S. D. Flint, A. E. Barkley, R. J. Ryel, and R. L. Lindroth. 2016. Rapid modulation of ultraviolet shielding in plants is influenced by solar ultraviolet radiation and linked to alterations in flavonoids. Plant, Cell \& Environment 39:222-230.

Bates, D., M. Maechler, B. Bolker, and S. Walker. 2015. Fitting linear mixed-effects models using lme4. Journal of Statistical Software 67:1-48.

Beckmann, M., M. Hock, H. Bruelheide, and A. Erfmeier. 2012. The role of UV-B radiation in the invasion of Hieracium pilosella - a comparison of German and New Zealand plants. Environmental and Experimental Botany 75:173-180.

Blossey, B., and R. Nötzold. 1995. Evolution of increased competitive ability in invasive non-indigenous plants: a hypothesis. Journal of Ecology 83:887-889.

Bodeker, G. E., H. Shiona, R. Scott-Weekly, K. Oltmanns, P. King, H. Chisholm, and R. L. McKenzie. 2006. UV Atlas version 2: What you get for your money. UV radiation and its effects: an update 8-9 https://www.niwa.co.nz/our-services/ online-services/uv-and-ozone/uv-atlasproj_desc

Chen, D., S. Wang, B. Xiong, B. Cao, and X. Deng. 2015. Carbon/nitrogen imbalance associated with drought-induced leaf senescence in Sorghum bicolor. PLoS ONE 10:1-17.

Chun, Y. J., M. L. Collyer, K. A. Moloney, and J. D. Nason. 2007. Phenotypic plasticity of native vs. invasive purple loosestrife: a two-state multivariate approach. Ecology 88:1499-1512.

Coffey, A., E. Prinsen, M. A. K. Jansen, and J. Conway. 2017. The UVB photoreceptor UVR8 mediates accumulation of UV-absorbing pigments, but not changes in plant morphology, under outdoor conditions. Plant, Cell \& Environment 40:2250-2260.

Colautti, R. I., and S. C. Barrett. 2013. Rapid adaptation to climate facilitates range expansion of an invasive plant. Science 342:364-366

Dietz, H., and P. J. Edwards. 2006. Recognition that causal processes change during plant invasion helps explain conflicts in evidence. Ecology 87:1359-1367.

Dlugosch, K. M., F. A. Cang, B. S. Barker, K. Andonian, S. M. Swope, and L. H. Rieseberg. 2015. Evolution of invasiveness through increased resource use in a vacant niche. Nature Plants 1:1-5.

Donohue, K., D. Messiqua, E. Hammond Pyle, M. S. Heschel, and J. Schmitt. 2000. Evidence of adaptive divergence in plasticity: density-and site-dependent selection on shade-avoidance responses in Impatiens capensis. Evolution 54:1956-1968.

Elst, E. M., K. P. Acharya, P. A. Dar, Z. A. Reshi, J. Tufto, I. Nijs, and B. J. Graae. 2016. Pre-adaptation or genetic shift 
after introduction in the invasive species Impatiens glandulifera? Acta Oecologica 70:60-66.

Erfmeier, A. 2013. Constraints and release at different scalesthe role of adaptation in biological invasions. Basic and Applied Ecology 14:281-288.

Escobar-Bravo, R., P. G. Klinkhamer, and K. A. Leiss. 2017. Interactive effects of UV-B light with abiotic factors on plant growth and chemistry, and their consequences for defense against arthropod herbivores. Frontiers in Plant Science 8:114

Felker-Quinn, E., J. A. Schweitzer, and J. K. Bailey. 2013. Metaanalysis reveals evolution in invasive plant species but little support for Evolution of Increased Competitive Ability (EICA). Ecology and Evolution 3:739-751.

Feng, Y. L., G. L. Fu, and Y. L. Zheng. 2008. Specific leaf area relates to the differences in leaf construction cost, photosynthesis, nitrogen allocation, and use efficiencies between invasive and noninvasive alien congeners. Planta 228:383-390.

Fenollosa, E., S. Munné-Bosch, and M. Pintó-Marijuan. 2017. Contrasting phenotypic plasticity in the photoprotective strategies of the invasive species Carpobrotus edulis and the coexisting native species Crithmum maritimum. Physiologia Plantarum 160:185-200.

Flory, S. L., F. Long, and K. Clay. 2011. Invasive Microstegium populations consistently outperform native range populations across diverse environments. Ecology 92:2248-2257.

Fraser, D. P., A. Sharma, T. Fletcher, S. Budge, C. Moncrieff, A. N. Dodd, and K. A. Franklin. 2017. UV-B antagonises shade avoidance and increases levels of the flavonoid quercetin in coriander (Coriandrum sativum). Scientific Reports 7:17758.

Ghalambor, C. K., J. K. McKay, S. P. Carroll, and D. N. Reznick. 2007. Adaptive versus non-adaptive phenotypic plasticity and the potential for contemporary adaptation in new environments. Functional Ecology 21:394-407.

Godar, D. E. 2007. UV doses worldwide. Photochemistry and Photobiology 81:736-749.

Haider, S., C. Kueffer, P. J. Edwards, and J. M. Alexander. 2012. Genetically based differentiation in growth of multiple nonnative plant species along a steep environmental gradient. Oecologia 170:89-99.

Hock, M., M. Beckmann, R. W. Hofmann, H. Bruelheide, and A. Erfmeier. 2015. Effects of UV-B radiation on germination characteristics in invasive plants in New Zealand. NeoBiota 26:21-37.

Howell, C. J., and J. W. D. Sawyer. 2006. New Zealand naturalised vascular plant checklist. New Zealand Plant Conservation Network, Wellington, New Zealand.

Huang, Q. Q., X. Y. Pan, Z. W. Fan, and S. L. Peng. 2015. Stress relief may promote the evolution of greater phenotypic plasticity in exotic invasive species: a hypothesis. Ecology and Evolution 5:1169-1177.

Hulme, P. E. 2008. Phenotypic plasticity and plant invasions: Is it all Jack? Functional Ecology 22:3-7.

Hulme, P. E. 2009. Trade, transport and trouble: managing invasive species pathways in an era of globalization. Journal of Applied Ecology 46:10-18.

Kataria, S., A. Jajoo, and K. N. Guruprasad. 2014. Impact of increasing Ultraviolet-B (UV-B) radiation on photosynthetic processes. Journal of Photochemistry and Photobiology B: Biology 137:55-66.

Kawecki, T. J., and D. Ebert. 2004. Conceptual issues in local adaptation. Ecology Letters 7:1225-1241.

Kueffer, C., C. C. Daehler, C. W. Torres-Santana, C. Lavergne, J. Y. Meyer, R. Otto, and L. Silva. 2010. A global comparison of plant invasions on oceanic islands. Perspectives in Plant Ecology, Evolution and Systematics 12:145-161.
Kuhlmann, F., and C. Müller. 2009. Development-dependent effects of UV radiation exposure on broccoli plants and interactions with herbivorous insects. Environmental and Experimental Botany 66:61-68.

Kuhlmann, F., and C. Müller. 2011. Impact of ultraviolet radiation on interactions between plants and herbivorous insects: a chemo-ecological perspective. Pages 305-347 in U. E. Lüttge, W. Beyschlag, B. Büdel, and D. Francis, editors. Progress in botany 72. Springer Science + Business Media, Berlin, Germany.

Kuznetsova, A., P. B. Brockhoff, and R. H. B. Christensen. 2016. lmerTest: tests in linear mixed effects models. $\mathrm{R}$ package version 2.0-33. https://CRAN.R-project.org/package=lme rTest

Lamarque, L. J., C. J. Lortie, A. J. Porté, and S. Delzon. 2015. Genetic differentiation and phenotypic plasticity in life-history traits between native and introduced populations of invasive maple trees. Biological Invasions 17:1109-1122.

Lande, R. 2015. Evolution of phenotypic plasticity in colonizing species. Molecular Ecology 24:2038-2045.

Leimu, R., and M. Fischer. 2008. A meta-analysis of local adaptation in plants. PLoS ONE 3:1-8.

Leishman, M. R., J. Cooke, and D. M. Richardson. 2014. Evidence for shifts to faster growth strategies in the new ranges of invasive alien plants. Journal of Ecology 102:1451-1461.

Lin, T., P. G. Klinkhamer, and K. Vrieling. 2015. Parallel evolution in an invasive plant: effect of herbivores on competitive ability and regrowth of Jacobaea vulgaris. Ecology Letters 18:668-676.

Llorens, L., F. R. Badenes-Pérez, R. Julkunen-Tiitto, C. Zidorn, A. Fereres, and M. A. Jansen. 2015. The role of UV-B radiation in plant sexual reproduction. Perspectives in Plant Ecology, Evolution and Systematics 17:243-254.

Lodge, D. M., et al. 2006. Biological invasions: recommendations for U.S. policy and management. Ecological Applications 16:2035-2054.

Maron, J. L., M. Vilà, R. Bommarco, S. Elmendorf, and P. Beardsley. 2004. Rapid evolution of an invasive plant. Ecological Monographs 74:261-280.

McKenzie, R. L., P. J. Aucamp, A. F. Bais, L. O. Björn, and M. Ilyas. 2007. Changes in biologically-active ultraviolet radiation reaching the Earth's surface. Photochemical \& Photobiological Sciences 6:218-231.

McKenzie, R. L., P. J. Aucamp, A. F. Bais, L. O. Björn, M. Ilyas, and S. Madronich. 2011. Ozone depletion and climate change: impacts on UV radiation. Photochemical \& Photobiological Sciences 10:182-198.

Molina-Montenegro, M. A., C. Palma-Rojas, Y. AlcayagaOlivares, R. Oses, L. J. Corcuera, L. A. Cavieres, and E. Gianoli. 2013. Ecophysiological plasticity and local differentiation help explain the invasion success of Taraxacum officinale (dandelion) in South America. Ecography 36:718-730

Mozdzer, T. J., and J. C. Zieman. 2010. Ecophysiological differences between genetic lineages facilitate the invasion of nonnative Phragmites australis in North American Atlantic coast wetlands. Journal of Ecology 98:451-458.

Müller, C. 2018. Evolution of increased competitive ability and shifting defence hypotheses. Pages 103-123 in J. M. Jeschke and T. Heger, editors. Invasion biology: hypotheses and evidence. CAB International, Wallingford, UK

Nicotra, A. B., et al. 2010. Plant phenotypic plasticity in a changing climate. Trends in Plant Science 15:684-692.

Oduor, A. M., R. Leimu, and M. van Kleunen. 2016. Invasive plant species are locally adapted just as frequently and at least as strongly as native plant species. Journal of Ecology 104:957-968. 
Oplaat, C., and K. J. Verhoeven. 2015. Range expansion in asexual dandelions: Selection for general-purpose genotypes? Journal of Ecology 103:261-268.

Parker, I. M., J. Rodriguez, and M. E. Loik. 2003. An evolutionary approach to understanding the biology of invasions: local adaptation and general-purpose genotypes in the weed Verbascum thapsus. Conservation Biology 17:59-72.

R Core Team. 2017. R: a language and environment for statistical computing. R Foundation for Statistical Computing, Vienna, Austria. https://www.R-project.org/

Richards, C. L., O. Bossdorf, N. Z. Muth, J. Gurevitch, and M. Pigliucci. 2006. Jack of all trades, master of some? On the role of phenotypic plasticity in plant invasions. Ecology Letters 9:981-993.

Robson, T., K. Klem, O. Urban, and M. A. Jansen. 2015. Reinterpreting plant morphological responses to UV-B radiation. Plant, Cell \& Environment 38:856-866.

Ruprecht, E., A. Fenesi, and I. Nijs. 2014. Are plasticity in functional traits and constancy in performance traits linked with invasiveness? An experimental test comparing invasive and naturalized plant species. Biological Invasions 16:1359-1372.

Schlaepfer, D. R., M. Glättli, M. Fischer, and M. van Kleunen. 2010. A multi-species experiment in their native range indicates pre-adaptation of invasive alienplant species. New Phytologist 185:1087-1099.

Schlichting, C. D., and M. Pigliucci. 1998. Phenotypic evolution: a reaction norm perspective. Sinauer Associates, Sunderland, Massachusetts, USA.

Seckmeyer, G., and R. L. McKenzie. 1992. Increased ultraviolet radiation in New Zealand (45 S) relative to Germany (48 N). Nature 359:135-137.

Si, C. C., Z. C. Dai, Y. Lin, S. S. Qi, P. Huang, S. L. Miao, and D. L. Du. 2014. Local adaptation and phenotypic plasticity both occurred in Wedelia trilobata invasion across a tropical island. Biological Invasions 16:2323-2337.

Štroch, M., Z. Materová, D. Vrábl, V. Karlický, L. Šigut, J. Nezval, and V. Špunda. 2015. Protective effect of UV-A radiation during acclimation of the photosynthetic apparatus to UV-B treatment. Plant Physiology and Biochemistry 96:90-96.

Suchar, V. A., and R. Robberecht. 2014. Integration and scaling of UV-B radiation effects on plants: from DNA to leaf. Ecology and Evolution 5:2544-2555.
Suchar, V. A., and R. Robberecht. 2016. Integration and scaling of UV-B radiation effects on plants: from molecular interactions to whole plant responses. Ecology and Evolution 6:4866-4884.

Turner, K. G., H. Fréville, and L. H. Rieseberg. 2015. Adaptive plasticity and niche expansion in an invasive thistle. Ecology and Evolution 5:3183-3197.

Ulm, R., and G. I. Jenkins. 2015. Q\&A: How do plants sense and respond to UV-B radiation? BMC Biology 13:1-6.

van Kleunen, M., and M. Fischer. 2005. Constraints on the evolution of adaptive phenotypic plasticity in plants. New Phytologist 166:49-60.

Vandepitte, K., T. Meyer, K. Helsen, K. Acker, I. Roldán-Ruiz, J. Mergeay, and O. Honnay. 2014. Rapid genetic adaptation precedes the spread of an exotic plant species. Molecular Ecology 23:2157-2164.

Verdaguer, D., M. A. Jansen, L. Llorens, L. O. Morales, and S. Neugart. 2017. UV-A radiation effects on higher plants: exploring the known unknown. Plant Science 255:72-81.

Wang, H., X. Ma, L. Zhang, E. Siemann, and J. Zou. 2015. UV-B has larger negative impacts on invasive populations of Triadica sebifera but ozone impacts do not vary. Journal of Plant Ecology 9:61-68.

Watanabe, S., T. Takemura, K. Sudo, T. Yokohata, and H. Kawase. 2012. Anthropogenic changes in the surface all-sky UV-B radiation through 1850-2005 simulated by an Earth system model. Atmospheric Chemistry and Physics 12:52495257.

Zenni, R. D., J. B. Lamy, L. J. Lamarque, and A. J. Porté. 2014. Adaptive evolution and phenotypic plasticity during naturalization and spread of invasive species: implications for tree invasion biology. Biological Invasions 16:635-644.

Ziska, L. H., M. B. Tomecek, M. Valerio, and J. P. Thompson. 2015. Evidence for recent evolution in an invasive species, Microstegium vimineum, Japanese stiltgrass. Weed Research 55:260-267.

Zuur, A. F., E. N. Ieno, N. J. Walker, A. A. Saveliev, and G. M. Smith. 2009. Mixed effects modelling for nested data. Pages 101-142 in M. Gail, K. Krickeberg, J. M. Samet, A. Tsiatis, and W. Wong, editors. Mixed effects models and extensions in ecology with R. Statistics for biology and health. Springer, New York, New York, USA.

\section{SUPPORTING INFORMATION}

Additional supporting information may be found in the online version of this article at http://onlinelibrary.wiley.com/doi/ 10.1002/ecy.2665/suppinfo

\section{Data Availability}

Data are available from the Dryad Digital Repository: https://doi.org/10.5061/dryad.g2n986g 